\title{
Analytical study to evaluate the relation between vaginal Birth Order and pelvic organ prolapse quantification stages
}

\author{
Prachi Kushwaha, Sona Soni*
}

Department of Obstetrics and Gynecology, GMC, Bhopal, Madhya Pradesh, India

Received: 12 May 2019

Accepted: 15 July 2019

\section{*Correspondence:}

Dr. Sona Soni,

E-mail: sonasoni0123@gmail.com

Copyright: (c) the author(s), publisher and licensee Medip Academy. This is an open-access article distributed under the terms of the Creative Commons Attribution Non-Commercial License, which permits unrestricted non-commercial use, distribution, and reproduction in any medium, provided the original work is properly cited.

\begin{abstract}
Background: Pelvic organ Prolapse (POP) is the downward displacement of central pelvic organs that are normally located at the level of or adjacent to the vaginal vault. These conditions are common and affect a progressively larger percentage of women as age advances especially in the postmenopausal years.

Methods: Data were collected as a retrospective study. Thorough history was taken and physical examination was done. Demographic details of each patient were recorded including age, residence type, education and socioeconomic status. A detailed history of all the patients was obtained included parity, live birth and nutrition status.

Results: Most of the patients belong to birth order 4 or more than that [73 (62.9\%)] followed by birth order 3 [26 $(22.4 \%)]$ and 2 [16 (13.8\%)] whereas $38(32.7 \%)$ patients had birth order $>4$. In patients with birth order $\geq 4$ and 3 had higher distribution of POPQ stage III and IV respectively.

Conclusions: From Present study it can be concluded that vaginal childbirth plays a major role in development of POP. POPQ stages were statistically significant with high birth order.
\end{abstract}

Keywords: Pelvic organs, POP, POPQ, Vaginal vault

\section{INTRODUCTION}

Pelvic organ Prolapse (POP) is the downward displacement of central pelvic organs that are normally located at the level of or adjacent to the vaginal vault. ${ }^{1}$ These conditions are common and affect a progressively larger percentage of women as age advances especially in the postmenopausal years. ${ }^{2}$

Although as many as $50 \%$ of women older than age 50 have some degree of POP, fewer than $20 \%$ seek treatment. It has been estimated that over the next 30 years, the demand for treatment of POP will increase $45 \%$, commensurate with an increase in the population of women older than 50 years of age. POP is a common and distressing condition. Whereas mortality from pelvic organ prolapse is negligible, significant morbidity or deterioration of lifestyle may be associated with prolapse. $^{1,3}$

In addition to mechanical discomfort, POP may negatively affect sexuality, body image and quality of life and is one of the most common reasons for gynecological surgery peaking in upper mid-life. Today the lifetime risk of POP surgery is reported to be $11-19 \%$ in welfare states.

POP is a rare condition in nulliparous women and in women after one or several caesarean sections, indicating that mode of delivery is more important than pregnancy alone. Obstetric trauma resulting from the passage of the fetus through the pelvic floor during vaginal delivery and increasing parity have been implicated as important risk factors for the development of POP. ${ }^{4}$ 
Various studies have identified age, vaginal childbirth and obesity as risk factors for POP. Other studies suggest that some POP are associated with diabetes, connective tissue disorders and neurological diseases. Some women have a genetic predisposition to the development of POP. ${ }^{5,6}$

Pelvic organ prolapse quantification system (POP-Q) refers to an objective, site-specific system for describing, quantifying, and staging pelvic support in women. ${ }^{7}$ It provides a standardized tool for documenting, comparing, and communicating clinical findings with proven interobserver and intra-observer reliability. In an effort to create an encoding tool useful to both the clinician and researcher, the Standardization Subcommittee of the International Continence Society created the Pelvic Organ Prolapse Quantification (POP-Q) system in 2002.

The POP-Q system gained the attention of the specialists all over the world, being approved by the International Continence Society (ICS), the American Urogynecologic Society (AUGS), and the Society of Gynecologic Surgeons for the description of female pelvic organ prolapse. It is the most common system used by gynecologists and urogynecologists, although other systems have been devised. This standardized quantification system facilitates communication between physician in practice and research and enables progression of POP to be followed accurately. The POP$\mathrm{Q}$ examination provides a standardized measurement to ensure uniform, reliable, and site-specific descriptions of POP and more accurate assessment of postoperative outcome. $^{7}$

\section{METHODS}

Present study entitled "Analytical study to evaluate the relation between vaginal birth order and POPQ stages" was conducted in the Department of Obstetrics and Gynecology, Gandhi Medical College and associated Sultania Zanana, Hospital, Bhopal. A total 116 patients, hospital based retrospective analytical study. Duration from 1st November 2015 to 31st March 2017. The study was conducted in the department of obstetrics and gynaecology, Gandhi Medical College and associated Sultania Zanana Hospital, Bhopal.

\section{Inclusion criteria}

- Patients with pelvic organ prolapse admitted in Sultania Zanana Hospital irrespective of age and birth order.

\section{Exclusion criteria}

- Patients with pelvic organ prolapse with history of con.

After the preliminary assessment with regards to the inclusion and exclusion criteria, informed consent was obtained from all the patients. Thorough history was taken and physical examination was done. Demographic details of each patient were recorded including age, residence type, education and socio- economic status. A detailed history of all the patients was obtained included parity, live birth and nutrition status.

\section{Statistical analysis}

Data were analyzed using Chi Square test (for categorical data), frequency distribution (for categorical data and findings the frequency and percentage) and Cross tabulation (for comparing multiple variable) using IBM SPSS ver. 20 software. Data are expressed as numbers and in percentages. Then the $\mathrm{p}$ value was obtained using Microsoft Excel software and Epical 1.0 software and the statistical significance of the results were compared.

\section{RESULTS}

In present study majority of patients were of age groups 51-60 years. Majority of patients belonged to rural area compared to urban area. Most of the patients were uneducated $[92(79.3 \%)]$. Majority of patients were having belonging to Upper lower class [77 (66.4\%)] followed by Lower [36 (31\%)]. Maximum patients had Average nutritional status [67 (57.8\%)] followed by poor status [28 (24.1\%)].

Most of the patients belong to the age groups of 51-60 years $[40(34.48 \%)]$ followed by $41-50$ years [30 $(25.86 \%)]$ and $31-40$ years [25 (21.55\%)] As POP is more common in age group of 51-60 years. Most of the patients belong to rural area $[80(69 \%)]$ compared to urban area [36 (31\%)] patients came from nearby town and villages. Since SZH is a old and eminent government medical college hospital and patients are referred here from primary and community health center.

Most of the patients belong to upper lower class [77 $(66.4 \%)]$ followed by lower [36 (31\%)]. This can be explained by the fact that $\mathrm{SZH}$ is a government medical college hospital which caters to the whole of Bhopal division. It has been providing its services free of cost to the all peripheral districts of the Bhopal division. Majority of patients comprise those of low socioeconomic strata. Most of the patients had Average nutritional status [67 $(57.8 \%)]$ followed by poor status. Most of the patients had Stage III [74 (63.8\%) followed by Stage IV [26 (22.4\%)] and Stage II [14 (12.1\%)].

Table 1: POPQ stages.

\begin{tabular}{|lll|}
\hline POPQ stages & Frequency & Percent \\
\hline Stage I & 2 & 1.7 \\
\hline Stage II & 14 & 12.1 \\
\hline Stage III & 74 & 63.8 \\
\hline Stage IV & 26 & 22.4 \\
\hline Total & $\mathbf{1 1 6}$ & $\mathbf{1 0 0}$ \\
\hline
\end{tabular}


Most of the patients belong to rural area [80 (69\%)] compared to urban area [36 (31\%)] Patients came from nearby town and villages. Since SZH is a old and eminent government medical college hospital and patients are referred here from primary and community health center. Patients of rural population have delay in seeking treatment because of shyness, later they present with higher stages of POPQ and associated comorbidities that cannot be dealt at primary and community health center. Patients of rural population have delay in seeking treatment because of shyness, later they present with higher stages of POPQ and associated comorbidities that cannot be dealt at primary and community health center.

Table 2: Association of residential area with the POPQ stages.

\begin{tabular}{|c|c|c|c|c|c|}
\hline \multirow{2}{*}{ Type of residence } & \multicolumn{4}{|c|}{ POPQ stage } & \multirow{2}{*}{ Total } \\
\hline & Stage I & Stage II & Stage III & Stage IV & \\
\hline Rural & 0 & 9 & 51 & 20 & 80 \\
\hline Urban & 2 & 5 & 23 & 6 & 36 \\
\hline Total & 2 & 14 & 74 & 26 & 116 \\
\hline
\end{tabular}

Table 3: Association of education status with POPQ stages.

\begin{tabular}{|c|c|c|c|c|c|}
\hline \multirow{2}{*}{ Education status } & \multicolumn{4}{|c|}{ POPQ stage } & \multirow{2}{*}{ Total } \\
\hline & Stage I & Stage II & Stage III & Stage IV & \\
\hline Educated & 1 & 2 & 16 & 5 & 24 \\
\hline Uneducated & 1 & 12 & 58 & 21 & 92 \\
\hline Total & 2 & 14 & 74 & 26 & 116 \\
\hline
\end{tabular}

Table 4: Association of birth order with POPQ stages.

\begin{tabular}{|c|c|c|c|c|c|c|}
\hline \multirow{2}{*}{ Birth order } & \multicolumn{4}{|c|}{ POPQ stage } & \multirow{2}{*}{ Total } & \multirow{2}{*}{ P value } \\
\hline & Stage I & Stage II & Stage III & Stage IV & & \\
\hline 1 & 0 & 0 & 1 & 0 & 1 & \multirow{4}{*}{0.002} \\
\hline 2 & 1 & 3 & 8 & 4 & 16 & \\
\hline 3 & 0 & 2 & 21 & 3 & 26 & \\
\hline$\geq 4$ & 1 & 9 & 44 & 19 & 73 & \\
\hline Total & 2 & 14 & 74 & 26 & 116 & \\
\hline
\end{tabular}

Most of the patients were uneducated [92 (79.3\%)]. As uneducated women were not aware about their healthrelated issue and because of lack of knowledge they did not visit health facility. Patients from rural area were having higher distribution in Stage III and IV compared to urban area patients $(p=0.014)$ There is less awareness about health services in rural population. As patients of rural population have delay in seeking treatment so later they present with progressive stage of POPQ In uneducated patients Stage III and IV POPQ was more distributed compared to Educated patients $(\mathrm{p}=0.002)$.

Most of the patients belong to birth order 4 or more than that $[73(62.9 \%)]$ followed by birth order 3 [26 (22.4\%)] and $2[16(13.8 \%)]$ whereas $38(32.7 \%)$ patients had birth order $>4$. Most cases were grand multipara as POP is more common in women with high birth order.POP was significantly high among the patients with higher birth order $(p=0.002)$. In patients with birth order $\geq 4$ and 3 had higher distribution of POPQ stage III and IV respectively.
Majority of patients were having birth order 4 or more than that $[73(62.9 \%)]$ followed by birth order 3 [26 $(22.4 \%)]$ and $2[16(13.8 \%)]$ whereas $38(32.7 \%)$ patients had birth order $>4$. Most cases were grand multipara as POP is more common in women with high birth order. Poor nutrition found to be the most commonly associated risk factor [28 (24.2\%)] followed by chronic cough [6(5.2\%)] constipation [5(4.3)] and diabetes mellitus [4(3.4)].

In present study most of the patients had Stage III [74 (63.8\%) followed by Stage IV [26 (22.4\%)] and Stage II [14 (12.1\%)]. Patients from rural area were having higher distribution in Stage III and IV compared to urban area patients $(p=0.014)$. Uneducated patients were having higher distribution in Stage III and IV compared to educated patients $(\mathrm{p}=0.002)$.

POP was significantly high among the patients with higher birth order $(\mathrm{p}=0.002)$. In patients with birth order $\geq 4$ and 3 had higher distribution of POPQ stage III and 
IV respectively. Home delivery cases were high compared to institutional delivery. Home delivery was found significantly associated with POP. Most of patients were uneducated and were having belonging to rural population. There is less awareness about health services in uneducated and rural population.

\section{DISCUSSION}

Present study entitled "Analytical study to evaluate the relation between vaginal birth order and POPQ stages" was conducted on 116 patients in department of obstetrics and gynecology, Gandhi Medical College and associated Sultania Zanana Hospital.

Pelvic organ prolapse (POP) is the bulge or protrusion of pelvic organs and their associated vaginal segments into or through the vagina. Pelvic prolapse occurs, in part, due to site-specific fascial defects that result in vaginal segment weakness.

Sze EH, Hobbs $\mathrm{G}$ et al did a prospective cross-sectional study with the purpose to evaluate the relation between vaginal birth and pelvic organ prolapse quantification (POPQ) stages III and IV prolapse and whether each additional vaginal birth is associated with an increase in pelvic support defects .They concluded vaginal birth is not associated with POPQ stages III and IV prolapse, but it is associated with an increase in POPQ stage II defect. ${ }^{8}$

Swift SE, Pound $\mathrm{T}$ et al did a case control study of etiologic factors in the development of severe pelvic organ prolapse The aim of this study was to identify etiologic factors predictive for the development of severe pelvic organ prolapse. Variables examined included age, gravidity, parity, number of vaginal deliveries, weight of largest infant delivered vaginally, menopause status, race, body mass index prior to pelvic surgery, and medical illnesses. The following four variables were selected in the regression analysis as predicting severe prolapse: age, weight of largest vaginal delivery, hysterectomy and previous prolapse surgery. Other variables that demonstrated statistically significant differences between groups were gravidity, parity, number of vaginal deliveries, menopausal status, race, history of incontinence surgery and the presence of hypertension. Variables that did not demonstrate any significant differences were body mass index, the presence of chronic obstructive pulmonary disease and diabetes mellitus. Advancing age, increasing weight of infants delivered vaginally, a history of hysterectomy and a history of previous prolapse surgery were found to be the strongest etiologic predictors of severe pelvic organ prolapse in our population. ${ }^{9}$

Little is known about the anatomic and physiologic changes in the pelvic floor that occur during pregnancy. The purpose of the study by O'boyle AL et al was to prospectively document pelvic organ support throughout pregnancy using the standardized system of the
International Continence Society, also known as the pelvic organ, prolapse quantification (POPQ) staging system. Overall POPQ stage was significantly higher in the third trimester than in the first $(\mathrm{P}=0.001)$. Individual POPQ points which showed significant differences between the first and third trimesters. These findings probably represent normal physiologic changes of the pelvic floor during pregnancy but suggest that significant changes may be objectively demonstrated prior to delivery. ${ }^{10}$

Seo JT, Kim JM, evaluated pelvic organ support and the prevalence of pelvic organ prolapse in Korean women using the pelvic organ prolapse-quantification system as the assessment tool. The study population consisted of 713 women 18 to 72 years old who were seen for annual Papanicolaou testing and pelvic examinations. Pregnant patients and patients who had delivered within the previous 6 weeks were not recruited. The overall distribution of pelvic organ prolapse quantification system stage was stages 0 to 4 in $68.3 \%, 19.9 \%, 11.2 \%$, $0.6 \%$ and $0.0 \%$ of patients, respectively. Vaginal size in Korean women differs from that in Western women. The prevalence of any degree of prolapse was approximately $31.7 \%$. Korean women were at relatively higher risk for anterior and posterior vaginal prolapse than for uterine prolapse. $^{11}$

Trowbridge ER et al studied distribution of pelvic organ support measures in a population-based sample of middle-aged, community-dwelling African American and white women in southeastern Michigan. The purpose of this study was to report the distribution of pelvic support among a population-based sample of middle-aged community-dwelling women, as defined by pelvic organ prolapse quantification (POP-Q) and study factors that might influence POP-Q measurements. In this population-based study of women from southeastern Michigan, $90 \%$ of the women had anterior and posterior vaginal wall support that was above or extended to the hymen. They concluded that increasing vaginal parity was associated with increasing descent of the anterior, posterior, and vaginal apex. ${ }^{12}$

The aim of the study done by Aytan H, Ertunç D et al was to assess the prevalence and the related factors of pelvic organ prolapse (POP) in a female population to whom health care services are offered. 1354 of the 3000 women admitted to the outpatient clinic were enrolled as they accepted to participate to the study. All women underwent vaginal examination to determine the degree of prolapse by pelvic organ prolapse quantification (POPQ) system. POP-Q stages $\geq 2$ were defined as prolapse. Women with and without prolapse were compared. Regression analysis was used in order to determine the independent predictors. POP was found to be associated with waist to hip ratio, parity, vaginal delivery, and menopausal status. Similar study was done by Elbiss HM, Osman $\mathrm{N}$ et al in which they studied 
prevalence, risk factors and severity of symptoms of pelvic organ prolapse among Emirati women. ${ }^{13,14}$

Sharma A, Zhang JP. Risk Factors and Symptoms of Uterine Prolapse: Reality of Nepali Women. Asian Women. The aim of the review was to explore the risk factors and symptoms of uterine prolapse (UP) experienced by Nepali women. The literature review was completed by making use of Pubmed, Google Scholar, and Medscape. The prevalence of uterine prolapse was found to be in the range of $10-40 \%$. The grass root causes of UP in Nepal are poverty, illiteracy and male dominated social structure. These causes gender based discrimination, inaccessibility to health services, poor nutrition, early marriage, early pregnancy, multi parity. ${ }^{15}$

Bradley CS, Nygaard IE et al studied vaginal wall descensus and pelvic floor symptoms with an objective to understand the clinical significance of early pelvic organ prolapse in older women. Vaginal support defects in older women are associated with obstructive urinary symptoms and the symptom of seeing or feeling a bulge. However, symptoms are not useful in discriminating between women with and without milder vaginal wall descensus. Based on these results, we suggest that other etiologies for bothersome bladder or bowel complaints be considered before performing surgery for early pelvic organ prolapse. ${ }^{16,17}$

Vaginal delivery is the major risk factor for the development of pelvic organ prolapse and urinary and fecal incontinence, resulting from damage to the pelvic floor muscles, nerves and connective tissue. The article by Bortolini MA, Drutz HP et al reviews the perineal trauma mechanism during vaginal delivery and discusses implications of current and future research projects. ${ }^{18}$

Luber KM et al did a study with the aim to assess current demand for care of pelvic floor disorders and create projections for future demand for care. They also sought to better understand the characteristics of women seeking care. Current demand for care was calculated by comparing those women seeking care through the female pelvic floor disorders clinic with those women of the same age range at risk within an integrated health care delivery program.

Patients underwent complete urogynecologic evaluation including cystometry. Women seeking care were compared with regard to age, distribution of conditions (pelvic organ prolapse, stress conditions, urge conditions), and probability of undergoing surgery. Modeling the study population by use of data from the US Census Bureau, which projects population changes over the next 30 years, created predictions of future demand? Stress conditions were more common among younger women and urge conditions were more common among older women. Pelvic organ prolapse was equally distributed throughout the age ranges. ${ }^{19}$
The present study had limitation of being small in sample size, a large randomized clinical trial is required to strengthen the results.

\section{CONCLUSION}

Vaginal childbirth plays a major role in development of POP. POPQ stages were statistically significant with high birth order. POPQ is a valid tool for assessment of POP. It has good reproducibility and introduces more objectivity in quantification of POP. It is an accurate and anatomically based assessment of the patient at the time of examination. It decreases significant amount of time needed to collect the desired data. POPQ has advantage of measuring descent in centimeter, it may be more discriminatory as regards treatment related changes over time. Other risk factors for POP were advance age, rural population, lack of education, low socioeconomic status, poor nutrition, home delivery and increase abdominal pressure from chronic cough, constipation and diabetes mellitus.

\section{What this study add to existing knowledge}

Over the next 30 years, growth in demand for services to care for female pelvic floor disorders will increase at twice the rate of growth of the same population. Demand for care for pelvic floor disorders comes from a wide age range of women, although mature age groups generate 10 times the number of consults per 1000 woman years as do their younger counterparts. Age plays a major role in the distribution of conditions with which patients present. These findings have broad implications for those responsible for administering programs to care for women, allocating research funds in women's health and geriatrics, and training physicians to meet this rapidly escalating demand.

\section{Funding: No funding sources Conflict of interest: None declared}

Ethical approval: The study was approved by the Institutional Ethics Committee

\section{REFERENCES}

1. Schaffer JI, Wai CY, Boreham MK. Etiology of pelvic organ prolapse. Clin Obstet Gynecol. 2005;48(3):639-47.

2. Wu JM, Hundley AF, Fulton RG, Myers ER. Forecasting the prevalence of pelvic floor disorders in US Women: 2010 to 2050. Obstetrics Gynecol. 2009;114(6):1278-83.

3. Hendrix SL, Clark A, Nygaard I, Aragaki A, Barnabei V, McTiernan A. Pelvic organ prolapse in the Women's Health Initiative: gravity and gravidity. Am J Obstet Gynecol. 2002;186(6):1160-6.

4. Swift S, Woodman P, O'boyle A, Kahn M, Valley M, Bland D, et al. Pelvic Organ Support Study (POSST): the distribution, clinical definition, and 
epidemiologic condition of pelvic organ support defects. Am J Obst Gynecol. 2005;192(3):795-806.

5. Handa VL, Harris TA, Ostergard DR. Protecting the pelvic floor: obstetric management to prevent incontinence and pelvic organ prolapse. Obstet Gynecol. 1996;88(3):470-8.

6. Moalli PA, Ivy SJ, Meyn LA, Zyczynski HM. Risk factors associated with pelvic floor disorders in women undergoing surgical repair. Obstet Gynecol. 2003;101(5):869-74.

7. Tegerstedt G, Miedel A, Mæhle-Schmidt M, Nyrén O, Hammarström M. Obstetric risk factors for symptomatic prolapse: a population-based approach. Am J Obst Gynecol. 2006;194(1):75-81.

8. Sze EH, Hobbs G. Relation between vaginal birth and pelvic organ prolapse. Acta Obstetricia Gynecol Scandinavica. 2009;88(2):200-3.

9. Swift SE, Pound T, Dias JK. Case control study of etiologic factors in the development of severe pelvic organ prolapse. Int Urogynecol J. 2001;12(3):187-92.

10. O'boyle AL, O'boyle JD, Ricks RE, Patience TH, Calhoun B, Davis G. The natural history of pelvic organ support in pregnancy. Int Urogynecol J. 2003;14(1):46-9.

11. Seo JT, Kim JM. Pelvic organ support and prevalence by Pelvic Organ Prolapse-Quantification (POP-Q) in Korean women. J Urol. 2006;175(5):1769-72.

12. Trowbridge ER, Fultz NH, Patel DA, DeLancey JO, Fenner DE. Distribution of pelvic organ support measures in a population-based sample of middleaged, community-dwelling African American and white women in southeastern Michigan. Am J Obstet Gynecol. 2008;198(5):548-e1.

13. Aytan H, Ertunç D, Tok EC, Yaşa O, Nazik H. Prevalence of pelvic organ prolapse and related factors in a general female population. Turkish $\mathbf{J}$ Obstet Gynecol. 2014;11(3):176.

14. Elbiss HM, Osman N, Hammad FT. Prevalence, risk factors and severity of symptoms of pelvic organ prolapse among Emirati women. BMC Urol. 2015;15(1):66.

15. Sharma A, Zhang JP. Risk factors and symptoms of uterine prolapse: reality of Nepali women. Asian Women. 2014;30(1):81-95.

16. Bradley CS, Nygaard IE. Vaginal wall descensus and pelvic floor symptoms in older women. Obstet Gynecol. 2005;106(4):759-66.

17. Baruwal A, Somronthong R, Pradhan S. Knowledge, attitude and preventive measures amongst married women of reproductive age towards uterine prolapse in the eight villages of Surkhet District of Nepal. J Health Res. 2011;25(3):129-33.

18. Bortolini MA, Drutz HP, Lovatsis D, Alarab M. Vaginal delivery and pelvic floor dysfunction: current evidence and implications for future research. Int Urogynecol J. 2010;21(8):1025-30.

19. Luber KM, Boero S, Choe JY. The demographics of pelvic floor disorders: current observations and future projections. Am J Obstet Gynecol. 2001;184(7):1496-503.

Cite this article as: Kushwaha P, Soni S. Analytical study to evaluate the relation between vaginal birth and pelvic organ prolapse quantification stages. Int J Reprod Contracept Obstet Gynecol 2019;8: 3067-72. 